\title{
Studies on Structural, Optical and Electrical Properties of ZnO Thin Films Prepared by the Spray Pyrolysis Method
}

\author{
L. C. Nehru' ${ }^{1}$, M. Umadevi ${ }^{1}$, C. Sanjeeviraja ${ }^{2, *}$ \\ ${ }^{1}$ Department of Physics, Mother Teresa Women's University, Kodaikanal, 624102, India \\ ${ }^{2}$ School of Physics, Alagappa University, Karaikudi, 630002, India
}

\begin{abstract}
Zinc oxide transparent thin films have been deposited on glass substrates by a pneumatic spray pyrolysis technique. Surface investigations such as AFM, SEM and XRD patterns of the films were investigated for as-deposited and annealed in air atmosphere. The morphology of the films is strongly related to the annealing temperature. By XRD, the amorphous phase is identified for as-deposited films and it changes to polycrystalline with the (lllllll $\left.\begin{array}{lll}0 & 0\end{array}\right)$ and $\left(\begin{array}{lll}1 & 0 & 1\end{array}\right)$ as preferential crystallographic orientation for annealed samples. The as-deposited films exhibited highest optical transmittance and the direct band gap energy was found to vary from 3.23 to $3.07 \mathrm{eV}$ with annealing temperatures. The electrical parameters of the samples were obtained by applying the dc four-probe technique. The effects of annealing environment on the luminescence characteristics of $\mathrm{ZnO}$ thin films were investigated by PL films are described here.
\end{abstract}

Keywords $\mathrm{ZnO}$, Thin film, Spray pyrolysis, Annealing temperature

\section{Introduction}

Transparent conductive oxide (TCO) consists of a degenerated wide band-gap semiconductor with low electrical resistivity and high transparency in the visible and near infrared wavelength range. A transparent conductive thin films including indium tin oxide (ITO) have many applications such as transparent electrodes, window materials in solar cell, light emitting diodes, flat panel displays and sensors[1-5]. However, high cost of ITO has motivated efforts to develop substitutes.

Recently, zinc oxide $(\mathrm{ZnO})$ with a hexagonal wurzite structure is a promising material to replace ITO in the above applications. It has a great interest in wide band gap semiconductors, because of the ever-increasing commercial desire for short wavelength light emitting devices. As a good candidate, $\mathrm{ZnO}$-nanostructured films have wideband-gap $(3.37 \mathrm{eV})$ and extremely large exciton binding energy of $60 \mathrm{mV}[6]$ at room temperature (RT), that provides more efficient excitonic lasing mechanism at RT. The efficiency and performance of any optical and electrical nanodevices are directly determined by the properties of underlying nanostructures, which are in turn greatly dependent on the crystallographic orientation, size, shape, and morphology. A highly transparent $\mathrm{ZnO}$ films have been prepared by many different deposition techniques and their corresponding deposition parameters play an important role in controlling

* Corresponding author:

sanjeeviraja@rediffmail.com (C. Sanjeeviraja)

Published online at http://journal.sapub.org/ijme

Copyright (C) 2012 Scientific \& Academic Publishing. All Rights Reserved the morphology and physical properties of the nanostructures. Both physical deposition, including thermal evaporation, sputtering, spray pyrolysis, metal organic chemical vapor deposition (MOCVD), pulsed laser deposition, molecular beam epitaxy (MBE) [7-15], and chemical synthetic routes, including hydrothermal, solvo-thermal, sol-gel, electrochemical, chemical bath deposition [16-26] have been successfully employed to prepare a wide variety of $\mathrm{ZnO}$ nanostructures. The physical deposition routes have the advantages of producing high-quality materials, but also the disadvantage of the need for high temperature.

Spray pyrolysis technology is a convenient for the deposition of semiconductor thin films and has the several advantages in comparison with other deposition techniques such as low cost of the source materials, producing highquality films using comparatively simple deposition equipment, moderate substrate temperatures, deposition scaled for large area and uniform deposition with very thin layers with specific composition, morphology, good adhesion between the deposited film and controlling the shape and sizes. The morphology of the material depends on the thermal treatment. Usually, as-deposited films require a thermal treatment to improve stability and reduce the possible undesirable influence of the substrate. It has been reported previously that high-purity crystalline $\mathrm{ZnO}$ thin films can be fabricated by spray pyrolysis. The key success of spray pyrolysis is using a single-solid organic zinc fountain as a precursor with the physical and chemical properties required depositing a pure film at the substrate. Thermal annealing is a widely used method to improve crystal quality and to study structural defects in materials. During an annealing process, dislocations and other structural defects 
will move in the material and adsorption/decomposition will occur on the surface, thus the structure and the stoichiometric ratio of the material will change. Such phenomena can have major effects on semiconductor device properties, light emitting devices being particularly affected. For $\mathrm{ZnO}$ films, many research groups have investigated the effects of annealing temperatures $\left(\mathrm{T}_{\mathrm{a}}\right)$ on the structure and luminescence properties of $\mathrm{ZnO}$ films[27,28]. In this paper, we report the preliminary results on the growth of $\mathrm{ZnO}$ thin films on glass substrates using hydrated zinc acetate $[\mathrm{Zn}$ $\left.\left(\mathrm{CH}_{3} \mathrm{COO}\right)_{2} \cdot 4 \mathrm{H}_{2} \mathrm{O}\right]$ as precursor in ethanol with tri-ethylene glycol (TEG). The aim of the present study is to investigate the general features of the annealing effect of the prepared $\mathrm{ZnO}$ thin films. Then, the films were characterized to examine the structural, electrical, optical and morphological properties are reported.

\section{Experimental}

Chemical spray pyrolysis is one of the major techniques used to deposit a wide variety of materials including metal or alloy oxides. Generally, spray pyrolysis deposition system which is mainly consists of the following four sections: (a) the reactants and carrier gas assembly connected to the spray nozzle at the entrance of the reaction chamber, (b) the reaction chamber in which there is a resistive heater used to heat the substrate to the required temperature for thin film deposition, (c) the temperature controller that monitors the deposition temperature and controls the desired substrate temperature and (d) the exhausting gas module. The substrate temperature was measured using a K-type thermocouple to an accuracy of $\pm 1 \mathrm{~K}$. This particular deposition technique involves the spraying of a fine mist of reactants onto planar hot substrates from a predetermined distance. Reactant droplets ending up in the substrates can undergo several phases, for example evaporation, solute condensation and thermal decomposition of volatile byproducts, which result in film formation. In the present work, $\mathrm{ZnO}$ films were prepared on corning microscope glass (of $1 \mathrm{~cm} 2$ geometric area) substrates using metal-organic zinc acetate di hydrate (Merck; > 99\%) precursor in air atmosphere at a fixed substrate temperature of $300^{\circ} \mathrm{C}$. The spray solution was prepared by dissolving amounts of zinc acetate for predefined molarity in the solvent containing $80 \%$ of ethanol, $10 \%$ of hydrochloric acid and $10 \%$ of tri-ethylene glycol (TEG) were mixed directly well by vigorous magnetic stirring for $1 \mathrm{~h}$. Ethanol has a very low boiling point $\left(\sim 80^{\circ} \mathrm{C}\right)$ and therefore, high substrate temperature causes the spray solution cone to partially evaporate even before they hit the substrate. This makes the surface morphology of the deposited films highly uneven and powdery. In order to prevent these undesired morphologies, TEG is added, which has a high boiling point $\left(\sim 280^{\circ} \mathrm{C}\right)$. Addition of TEG reduces both premature evaporation of the solvent in the spray cone while in transit from the spray nozzle to the substrate and the resultant loss of material during the condensation due to the substrate tem- perature. The spraying solution is always buffered by a small amount of $\mathrm{HCl}$ to increase the solubility and prevent precipitation in the solution.

In this technique, substrate cleaning plays an important role in the deposition of thin films. First, commercially available microscope glass were boiled in chromic acid for 2 $\mathrm{h}$, washed with detergent, rinsed three times in acetone and finally ultrasonically cleaned with distilled water before use. Each rinse for fifteen minutes; and then rinsed in ethanol for fifteen minutes they were put into the deposition chamber. The spray flow rate was fixed at about $0.3 \mathrm{ml} \mathrm{min}^{-1}$, and the distance between the spray gun nozzle and the substrate was placed parallel to the target surface with a $20 \mathrm{~cm}$. The flow rate used and the spraying distance were optimized via several additional pre-tests for the best continuity of the films. In the present experiment, the heater block temperature is considered as the substrate temperature, which was kept at $300^{\circ} \mathrm{C}$, and the deposited time was $10 \mathrm{~min}$. The temperature of the substrates was fixed at a constant temperature and the temperature was measured by a standard K-type thermocouple. After spray pyrolysing, as-deposited $\mathrm{ZnO}$ thin films were removed from the spray pyrolysing chamber and were immediately rapid thermal annealing at tube furnace at various temperatures were increased from $350^{\circ} \mathrm{C}$ to $450^{\circ} \mathrm{C}$. The heating rate was $6^{\circ} \mathrm{C} / \mathrm{s}$ and the dwell time was $1 \mathrm{~h}$. After annealing, the samples were taken out for characterization. The thicknesses of the deposited films were in the range of $0.96 \mu \mathrm{m}$. The Phase purity and the crystallinity of the films was characterized by X-ray diffraction (XRD) using a ' $\mathrm{X}$ ' Pert PRO PANalytical system with Ni filtered $\mathrm{Cu} \mathrm{K} \alpha$ irradiation $(\lambda=1.5460 \AA, 30 \mathrm{kV}$ and $40 \mathrm{~mA})$. The surface morphology was characterized using a Dimension-3000 atomic force microscope (AFM), the cross-sectional morphology being evaluated with a Hitachi S-4500 scanning electron microscope (SEM). The samples for SEM imaging were coated with a thin layer of gold film to avoid charging. The optical transmission spectra of the films were measured at room temperature in air using a double beam spectrophotometer (Hitachi) in the wavelength range of 300 to 900 $\mathrm{nm}$. The photoluminescence (PL) characteristics of $\mathrm{ZnO}$ films were investigated by making photoluminescence measurements using a Varian model Cary Eclipse fluorescence spectrophotometer. A $15 \mathrm{~W}$ Xenon pulse lamp with a wavelength of $320 \mathrm{~nm}$ is used as the excitation light source, was used to evaluate the optical properties of the $\mathrm{ZnO}$ films. The electrical resistivity (or resistance) were characterized via Hall Effect measurements (Bio-Rad, HL5500PC) were carried out in a four-point Van der Pauw configuration with indium ohmic electrodes at room temperature. All the measurements were carried out at room temperature.

\section{Results and Discussion}

The XRD patterns of the spray pyrolysis coated as- deposited $\mathrm{ZnO}$ and annealed $\mathrm{ZnO}$ films are shown in Fig. 1. The intensity data were collected over a range $2 \theta$ is 20 to $80^{\circ}$. 
Figs show the plots of intensity (in arbitrary unit) against $2 \theta$. The result indicates that the films have a polycrystalline hexagonal wurtzite structure with $\left(\begin{array}{lll}1 & 0 & 0\end{array}\right)$ and (llll $\left.10 \begin{array}{ll}1 & 1\end{array}\right)$ orientation. In Fig. 1(a) pattern shows that it was an amorphous phases for the as-deposited $\mathrm{ZnO}$ film. As the film was annealed at various temperatures the XRD pattern of $\mathrm{ZnO}$ at $350^{\circ} \mathrm{C}$ (Fig. 1 (b)) shows very weak $\left(\begin{array}{lll}1 & 0 & 0\end{array}\right)$ and $\left(\begin{array}{lll}1 & 0 & 1\end{array}\right)$ diffraction peaks. Fig. 1(c) shows a strong X-ray peak from (10 0) planes with a weak $\left(\begin{array}{lll}1 & 0 & 1\end{array}\right)$ peak at $400^{\circ} \mathrm{C}$. As the annealed temperature was increased further to $450^{\circ} \mathrm{C}$, the intensity of the $\left(\begin{array}{lll}1 & 0 & 0\end{array}\right)$ peak in pattern $(d)$ decreased in comparing with the pattern Fig. 1 (c), but (lll $\left.\begin{array}{lll}1 & 0 & 1\end{array}\right)$ peak did not change. The (1 0 0) peak intensity is increased and then decreased with increasing temperature over the selected annealing temperature. The average sizes of crystallites (D) were calculated from the full width at half maximum (FWHM) of the diffraction peaks from the $\left(\begin{array}{lll}1 & 0 & 0\end{array}\right)$ and $\left(\begin{array}{lll}1 & 0 & 1\end{array}\right)$ planes of the films with the help of Scherrer formula[29]. The average crystallite size is 39,85 and $60 \mathrm{~nm}$ were calculated for the annealed $\mathrm{ZnO}$ thin films, respectively.

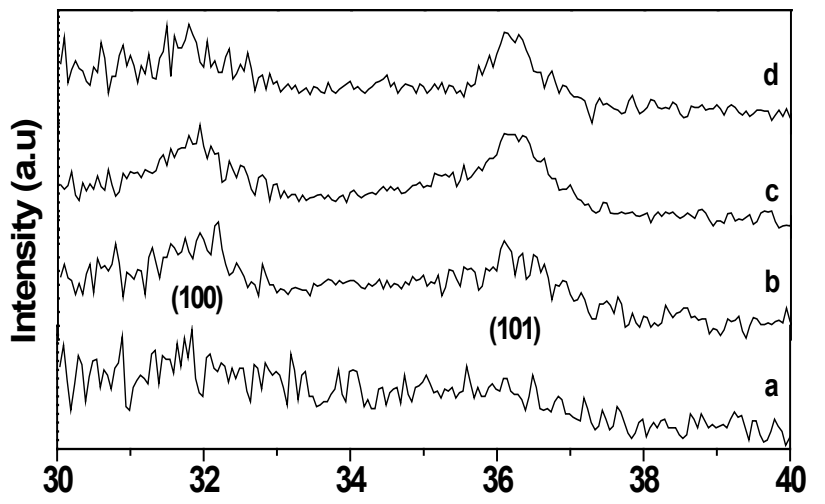

\section{$2 \theta$}

Figure 1. XRD pattern of (a) as-deposited; (b) annealed at $350^{\circ} \mathrm{C}$; (c) $400^{\circ} \mathrm{C}$ and (d) $450^{\circ} \mathrm{C}$

Using XRD data, the lattice parameters (a and c) are be calculated from $1 / \mathrm{d}={ }^{2} / 3\left[\left(\mathrm{~h}^{2}+\mathrm{hk}+\mathrm{k}^{2}\right) / \mathrm{a}^{2}\right]+\mathrm{l}^{2} / \mathrm{c}^{2}$, cell volumes $(\mathrm{v})$ can be calculated from $0.866 \mathrm{a}^{2} \mathrm{c}$, dislocation density $(\delta)$ can be calculated from $\delta=1 / \mathrm{D}^{2}$ and the micro strain $(\varepsilon)$ can be calculated from $\varepsilon=(\lambda / D \sin \theta)-(\beta / \tan \theta)$ which will elucidate the nature of the prepared $\mathrm{ZnO}$ films. The measured line-widths and the other physical parameters are calculated and are given in Table 1.

From the Table 1, it can be concluded that the crystallite size increases due to the heat treatment as also clearly shown by the SEM images (as shown in Fig. 2), and decrease in dislocation density and strain is due to the manifestation of dislocation network on the film surface. This formation of the films is high quality films. The average lattice parameters and cell volumes are close and good agreement with the standard results. It is well known that the heat treated film samples lattice parameters are temperature dependent, i.e. leads to shrink of the lattice.

The morphology of the as-deposited (Fig. 2a) $\mathrm{ZnO}$ thin film was also observed at higher magnification is made up of very small grains and it can be seen that the grains are packed closely and well distributed on the glass substrate. Fig. 2b\&c shows for the films annealed at $400^{\circ} \mathrm{C}$ and $450^{\circ} \mathrm{C}$, the grains are larger in size compared to the as-deposited $\mathrm{ZnO}$ and that may be due to the crystallite growth by heat treatment. The grains were uniformly stacked up, interact with each other and entirely compact are visible. It can be concluded that the annealed temperature has a great influence on the film surface. Further, it clearly evidences that each grain is made up with an agglomeration of (nanometer size) very small crystallites.
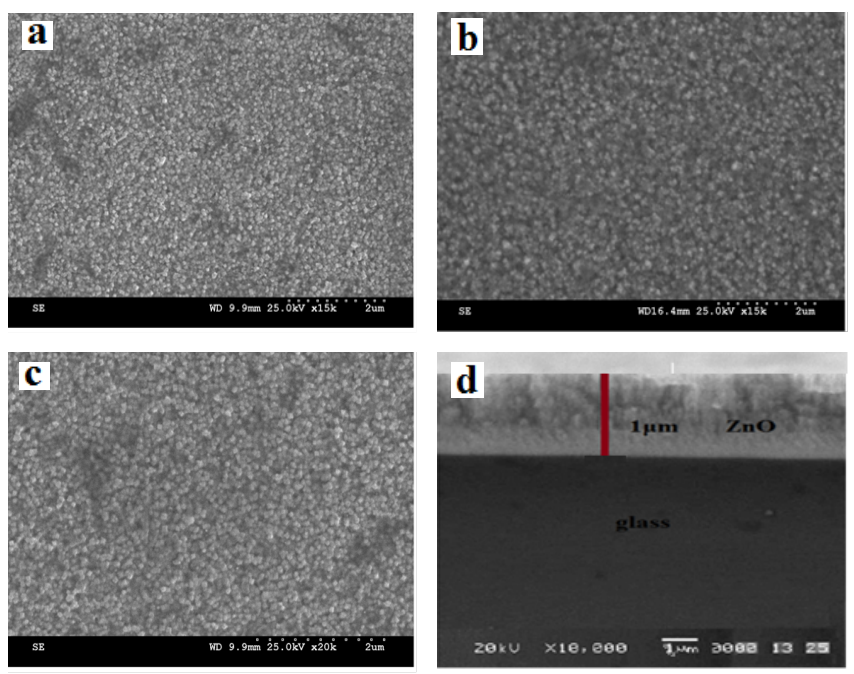

Figure 2. SEM images of $\mathrm{ZnO}$ films (a) as-deposited; (b) annealed at $400^{\circ} \mathrm{C}$; (c) annealed at $450^{\circ} \mathrm{C}$ and (d) cross-sectional SEM morphology of sample film $\mathrm{c}$ in Fig. 1.

Table 1.

\begin{tabular}{|c|c|c|c|c|c|c|c|c|}
\hline \multirow[b]{2}{*}{$\begin{array}{c}\text { Annealing } \\
\text { temperatures }\end{array}$} & \multirow[b]{2}{*}{$\begin{array}{l}\text { Reflecting } \\
\text { plane (hkl) }\end{array}$} & \multicolumn{2}{|c|}{ D spacing $(A)$} & \multicolumn{2}{|c|}{ Lattice constant $(A)$} & \multirow[b]{2}{*}{$\begin{array}{l}\text { Crystalline } \\
\text { size, } D(n m)\end{array}$} & \multirow[b]{2}{*}{$\begin{array}{c}\text { Dislocation den- } \\
\text { sity, } \delta \\
10^{11} \text { Lines } / \mathrm{cm}^{2}\end{array}$} & \multirow[b]{2}{*}{$\begin{array}{c}\text { Strain, } \varepsilon \\
10^{-3}\end{array}$} \\
\hline & & Observed & $\begin{array}{c}\text { JCPDS } \\
\text { Standard } \\
(89-1397) \\
\end{array}$ & Observed & Standard & & & \\
\hline \multirow{2}{*}{$350^{\circ} \mathrm{C}$} & $(100)$ & 2.8034 & 2.8171 & \multirow{2}{*}{$\begin{array}{l}a=3.241 \\
c=5.261\end{array}$} & \multirow{2}{*}{$\begin{array}{l}\mathrm{a}=3.253 \\
\mathrm{c}=5.213\end{array}$} & \multirow{2}{*}{39} & \multirow{2}{*}{0.6574} & \multirow{2}{*}{3.022} \\
\hline & (101) & 2.4814 & 2.4784 & & & & & \\
\hline \multirow{2}{*}{$400^{\circ} \mathrm{C}$} & $(100)$ & 2.8153 & 2.8171 & \multirow{2}{*}{$\begin{array}{l}\mathrm{a}=3.294 \\
\mathrm{c}=5.151\end{array}$} & \multirow{2}{*}{$\begin{array}{l}a=3.253 \\
c=5.213\end{array}$} & \multirow{2}{*}{85} & \multirow{2}{*}{0.1340} & \multirow{2}{*}{1.398} \\
\hline & $(101)$ & 2.4820 & 2.4784 & & & & & \\
\hline \multirow{2}{*}{$450^{\circ} \mathrm{C}$} & $(100)$ & 2.8097 & 2.8171 & \multirow{2}{*}{$\begin{array}{l}a=3.267 \\
c=5.177\end{array}$} & \multirow{2}{*}{$\begin{array}{l}a=3.253 \\
c=5.213\end{array}$} & \multirow{2}{*}{60} & \multirow{2}{*}{0.2777} & \multirow{2}{*}{1.986} \\
\hline & (101) & 2.4813 & 2.4784 & & & & & \\
\hline
\end{tabular}


The planar and three-dimensional AFM surface morphology of the entire specimen has a smooth and homogeneous. Fig. 3 shows the as-deposited films have a granular morphology. However, in the case of annealed film sample, the surface had a complete different morphology, which was mainly dominated by grains agglomerations, some isolated $\mathrm{ZnO}$ islands, very tall features and smooth surface with rms surface roughness was measured as 153,119 and $97 \mathrm{~nm}$ and a surface grain size derived as described above from the AFM measurements is about 63, 132 and $108 \mathrm{~nm}$ for as-deposited and annealed with 400 and $450^{\circ} \mathrm{C}$ film samples with in the scan area of $5 \times 5 \mu \mathrm{m}$ which were analyzed by the software package Spiwin Soft. The thickness of the films is an important parameter in coating technology. The nature and quality of an oxide semiconductor films mainly depends on its thickness due to the face that it modifies the atomic orientations, defect structures and the resulting optical properties. So in our experiments, the distance between the spray gun nozzle and the substrate were fixed at a constant flow rate. The thickness of the film is about $\sim 1 \mu \mathrm{m}$. The image shows that the film is very dense with columnar structure normal to the surface of the substrate. It can be seen that the grain size near the interface is much smaller than that on the surface of the film, which is considered as competitive growth of the deposited film[30].

The electrical transport properties of $\mathrm{ZnO}$ films strongly depend on their structure (grain size and shape, defects etc), purity (concentration of impurities like absorbed and adsorbed gases, moisture, etc) and on the preparation conditions. The film thickness is dependent on the electrical resistivity $(\rho)$, Hall mobility $(\mu)$ and carrier concentration (n) of the prepared thin films. In this experiment, $\mathrm{ZnO}$ films were coated at constant time duration. The results revealed that all the films are degenerate n-type semiconductors. The as-deposited film exhibits a resistivity of $\sim 2.7 \times 10^{-3} \Omega \mathrm{cm}$ and carrier concentration of $\sim 1.3 \times 10^{21} \mathrm{~cm}^{-3}$. When the annealed temperature increases at $450^{\circ} \mathrm{C}$, the resistivity decreases to the minimum value of $\sim 4.71 \times 10^{-4} \Omega \mathrm{cm}$, which is due to the improved $\mathrm{ZnO}$ crystallinity, as indicated by XRD results. The results of Hall mobility also undergoes a sharp increase, which results from the greatly weakened carrier scattering process due to the improvement of crystallinity. Both carrier concentration and Hall mobility increase in the decrease of resistivity. The maximum carrier concentration and Hall mobility is $2.14 \times 10^{21} \mathrm{~cm}^{-3}$ and $9.11 \mathrm{~cm}^{2} / \mathrm{Vs}$ respectively, which are obtained for as-deposited film. Further annealing temperature causes slight degradation of the electrical properties. The decrease in conductivity is attributed to an increase in chemisorbed oxygen, which acts as electron trap and hence decreases of carrier concentration[31]. The decrease of carrier mobility may be related to the increase of grain boundary scattering of the free electrons.

Figure 4 shows a typical optical transmission (\% T) spectrum of a $2 \times 2 \mathrm{~cm} \mathrm{ZnO}$ film in the wavelength range of $300-900 \mathrm{~nm}$. The spectra were taken using air as the optical reference. The average $\% \mathrm{~T}$ in the visible range for all the films is $\sim 80 \%$. The as-deposited $\mathrm{ZnO}$ thin films were found to be highly transparent in the visible wavelength region with an average $\% \mathrm{~T}$ of $\sim 85 \%$. The high transmission indicates the very good optical quality (which is obtained due to uniform oxidation and improvement in lattice arrangements) and associated with a good structural homogeneity and crystallinity of the prepared $\mathrm{ZnO}$ thin films from zinc acetate bath. As the annealed temperature is $400^{\circ} \mathrm{C}$, the $\% \mathrm{~T}$ is lower than the as-deposited film sample. However, when the annealed temperature is $450^{\circ} \mathrm{C}$, the $\% \mathrm{~T}$ is higher than the annealed at $400^{\circ} \mathrm{C}$ film sample signifies the small particle size.
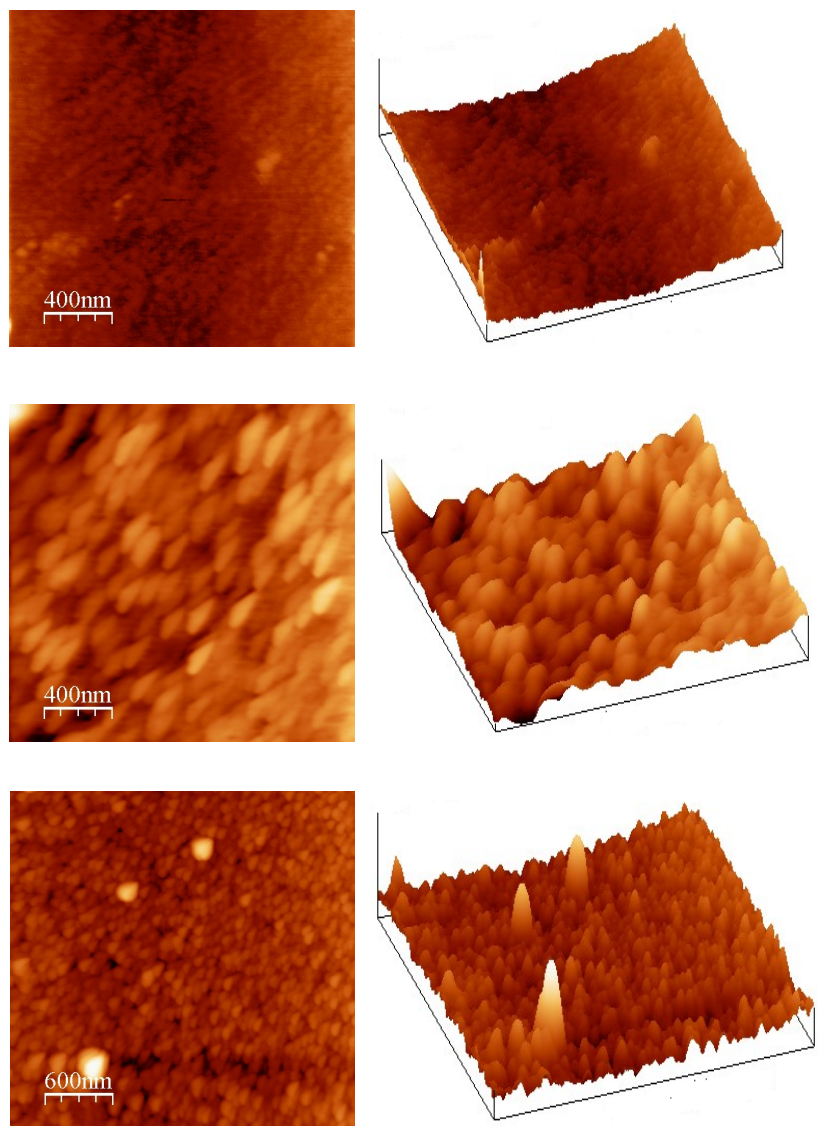

Figure 3. AFM images of as-deposited and annealed sample film $\mathrm{c}$ and $\mathrm{d}$ in Fig. 1.

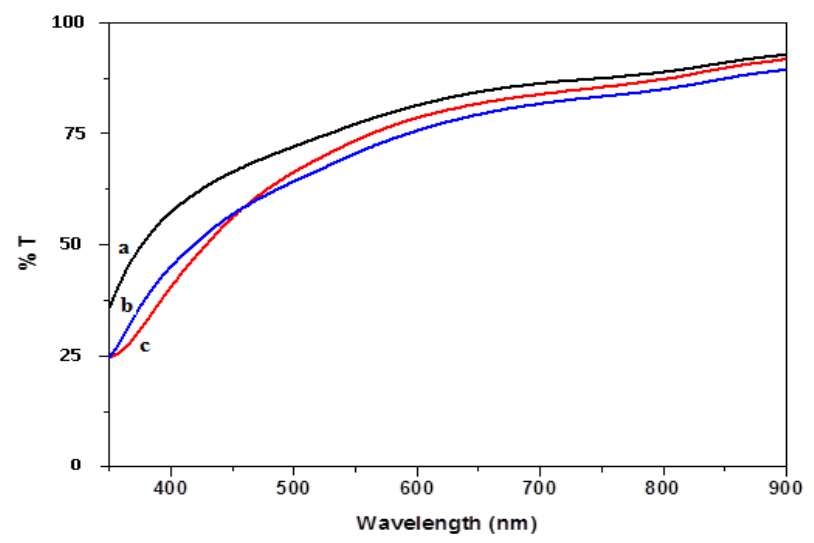

Figure 4. Transmittance spectra of $\mathrm{ZnO}$ thin films prepared at different annealed temperature: (a) as-deposited; (b) $400^{\circ} \mathrm{C}$ and (c) $450^{\circ} \mathrm{C}$.

The direct optical energy gap Egap was derived has assuming a direct transition between the edges of the valence 
and the conduction band, for which the variation in the absorption coefficient with the photon energy $h v$ is given by

$$
\alpha(\mathrm{h} v)=\mathrm{A}\left(\mathrm{h} v-\mathrm{E}_{\mathrm{gap}}\right)^{1 / 2}
$$

In the above equation, $\mathrm{E}_{\text {gap }}$ denotes the optical energy gap between the valence and the conduction band. "Tauc" plots of $\alpha^{2}$ versus $h v$ were given by extrapolation of the linear region of the resulting curve. The optical band gap value $\mathrm{E}_{\text {gap }}$ is as shown in Fig.5. The calculated band gap energy $\left(\mathrm{E}_{\mathrm{g}}\right)$ of as-deposited is $3.23 \mathrm{eV}$; whereas the films processed at 400 and $450^{\circ} \mathrm{C}$ is 3.07 and $3.14 \mathrm{eV}$ respectively. The variations of the optical energy gap could be attributed to changes in the annealing temperatures. Generally, it can be stated that the reduced band gap energy of $\mathrm{ZnO}$ may be due to the extent of non-stoichiometry of the deposited layers.

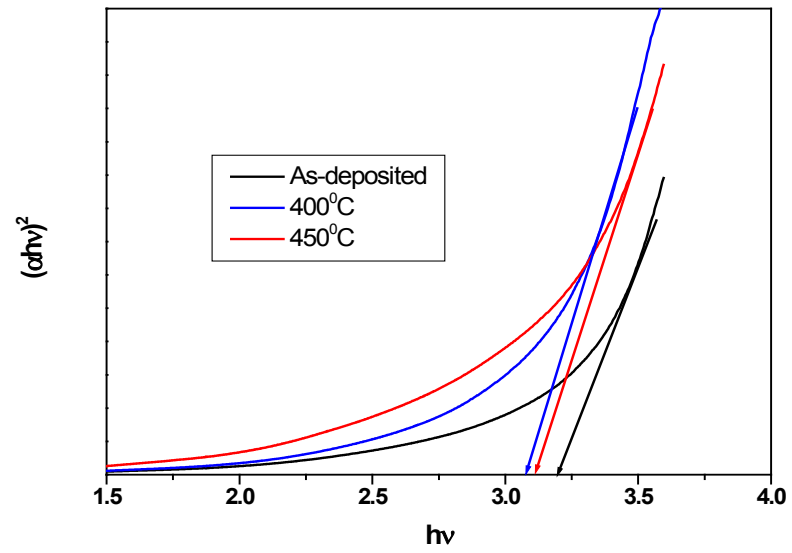

Figure 5. Band gap variation as a function of annealing temperature

But, interestingly these observed band gap energies of $\mathrm{ZnO}$ films are invariably lower than the band gap value of bulk $\mathrm{ZnO}(3.37 \mathrm{eV})$ which may be due to the various lattice associated atomic interaction phenomena come into play from its ionic crystalline lattice nature[32]. The band gap variation is entirely different in thin films compared to bulk material. Here the energy gap between the conduction band and the valence band is perturbed which depends on the following electronic structure characteristics[33,34] (i) the Madelung energy due to charge-charge interactions in the system, (ii) the delocalization energy due to electron sharing between atoms, (iii) the internal energy due to the filling of atomic orbital and intra-atomic electron-electron interactions and (iv) the short-range repulsion energy between atoms that makes the atoms not to come close to each other. In addition, the presence of oxygen vacancies also induces changes in the electronic structure of surfaces. On planner surfaces, the Madelung potential is weakened leading to a reduction of the ionic gap and in turn its total band gap becomes smaller compared to bulk.

Figure 6 shows the photoluminescence (PL) spectra of $\mathrm{ZnO}$ films under excitation of $325 \mathrm{~nm}$. From the spectra, it may be observed that the positions and intensities of the PL peak are both effected by annealing temperatures. There are two main peaks located at about violet $(418 \mathrm{~nm})$ and green $(525 \mathrm{~nm}$ ) for all the film samples (curve a, b, c and d). When the films annealed at $400^{\circ} \mathrm{C}$ (curve c), violet peak is shifted to higher wavelength (red shift) and further shifted with the increase of annealing temperatures at $450^{\circ} \mathrm{C}$ (curve d), PL intensities decrease and simultaneously, the violet peak exhibits a blue shift believed to originate from the change of stress along the lattice distortion, whereas no shift in PL green peaks was observed over the whole range of temperature examined. According to XRD analysis, the stress changed from compressive to a tensile one. If the tensile is accumulated, the band-gap energy is increased[35]. According to quantum confinement theory, the energy band gap of a semiconductor depends on the crystal size; its value will increase with a decrease in crystal size. The $418 \mathrm{~nm}$ violet luminescence is ascribed to radiative defects related to the interface traps existing at grain boundaries. For the violet peak is attributed to free excitonic emission because of the high exciton binding energy of $60 \mathrm{meV}$. On the other hand, interface traps are reported to lie within the depletion regions located at the $\mathrm{ZnO}-\mathrm{ZnO}$ grain boundaries[38] and have been found to the conduction band edge, which suggest that the observed $418 \mathrm{~nm}$ violet luminescence is due to associated radiative defects and green emission is commonly observed for $\mathrm{ZnO}$, and is attributed to oxygen deficiency[36,37].

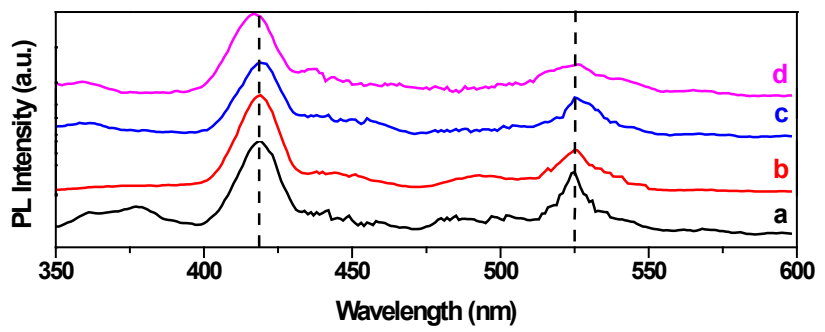

Figure 6. PL spectra of $\mathrm{ZnO}$ films (a) as-deposited; (b) annealed at $350^{\circ} \mathrm{C}$; (c) $400^{\circ} \mathrm{C}$ and (d) $450^{\circ} \mathrm{C}$

\section{Conclusions}

Zinc oxide films have been successfully prepared on glass substrates using the spray pyrolysis technique. The process parameters were optimized to have good quality crystalline films. The films were optically clear, adherent and uniform. XRD characterization of the annealing films revealed polycrystalline. AFM studies confirmed the uniformity and well grown crystalline morphology of the $\mathrm{ZnO}$ films. The effect of annealing temperatures on electrical and optical properties of the films was studied. A highest resistivity of $\sim 2.7 \times 10-3$ $\Omega \mathrm{cm}$ is obtained for the as-deposited $\mathrm{ZnO}$ film sample. All the films were transparent in the visible region; with an average optical transmittance of $80 \%$. The mechanism of violet and green luminescence emission from $\mathrm{ZnO}$ thin films annealed at various temperatures was investigated.

\section{ACKNOWLEDGEMENTS}

One of the authors, L. C. Nehru would like to thank DST-CURIE Program, India for the financial support under Research Associate to carry out this research work at De- 
partment of Physics, Mother Teresa Women's University, Kodaikanal-624 102, India

\section{REFERENCES}

[1] E. Fortunato, P. Barquinha, A. Pimentel, A. Goncalves, A. Marques, L. Pereira, R. Martins, Thin Solid Films 2005, 487, 205.

[2] K. Iwata, T. Sakemi, A. Yamada, P. Fons, K. Awai, T. Yamamoto, S. Shirakata, K. Matsubara, H. Tampo, K. Sakurai, S. Ishizuka, S. Niki, Thin Solid Films 2003, 445, 274.

[3] J. Yoo, J. Lee, S. Kim, K. Yoon, I. Jun Park, S.K. Dhungel, B. Karunagaran, D. Mangalaraj and Junsin Yi, Thin Solid Films 2005, 480, 213.

[4] MA. Martı'nez, J. Herrero, MT. Gutie'rrez, Sol Energy Mater Sol Cells 1997, 45, 75.

[5] Z.L. Wang, J. Nanosci. Nanotech. 2008, 8, 27.

[6] Y. Zhizhen, M. Dewei, H. Junhui, J Crystal Growth 2003, 256, 78 .

[7] Debabrata Pradhan, Shrey Sindhwani, K. T. Leung, Nanoscale Res Lett 2010, 5, 1727.

[8] P. Puspharajah, S. Radhakrishna, J Mater Sci 1997, 32, 3001.

[9] G. Zhang, M. Adachi, S. Ganjil, A. Nakamura, J. Temmyo, Y. Matsui, Jpn. J. Appl. Phys. Part 2, 2007, 46, L730.

[10] C. Gorla, N. Emanetoglu, S. Liang, W. Mayo, Y. Lu, M. Wraback, H. Shen, J Appl Phys 2000,85, 2595.

[11] B. Sang, K. Kushiya, D. Okumura, O. Yamase, Sol Energy Mater Sol Cells 2001, 67, 237.

[12] M. Lorenz, E.M. Kaidashev, A. Rahm, Th. Nobis, J. Lenzner, G. Wagner, D. Spemann, H. Hochmuth, M. Grundmann, Appl. Phys. Lett. 2005, 86, 143113.

[13] YR. Ryu, S. Zhu, JD. Budai, HR. Chandrasekhar, PF. Miceli, HW. White, Appl Phys Lett 2000, 88, 201.

[14] Y. Segawa, A. Ohtomo, M. Koinuma, ZK. Tang, P. Yu, GKL. Wong, Phys Stat Sol (b) 1997,202, 669.

[15] HB. Kang, K. Nakamara, SH. Lim, D. Shindo, Jpn J Appl Phys. 1998, 37, 781.

[16] C. Wang, B. Mao, E. Wang, Z. Kang, C. Tian, Solid State Commun. 2007, 141, 620.
[17] B. Liu, H.C. Zeng, Chem Mater 2007, 19, 5824.

[18] Y. Sun, N. George Ndifor-Angwafor, D.J. Riley, M.N.R. Ashfold, Chem. Phys. Lett. 2006, 431, 352.

[19] S. Kar, A. Dev, S. Chaudhuri, J. Phys. Chem. B 2006, 110, 17848.

[20] S.K.N. Ayudhya, P. Tonto, O. Mekasuwandumrong, V. Pavarajarn, P. Praserthdam, Cryst. Growth Des. 2006, 6, 2446.

[21] C.V. Santilli, S.H. Pulcinelli, M.S. Tokumoto, V. Briois, J. Eur. Ceramic Soc. 2007, 27, 3691.

[22] P. Bhattacharyya, P.K. Basu, H. Saha, S. Basu, Sens. Actuators B Chem. B 2007,124, 62.

[23] S. Peulon, D. Lincot, Adv. Mater. 1996, 8, 166.

[24] W. Peng, S. Qu, G. Cong, Z. Wang, Cryst. Growth Des. 2006, 6,1518 .

[25] B. Cao and W. Cai, J. Phys. Chem. C 2008,112, 680.

[26] L. Znaidi, GJAA. Soler Illia, S. Benyahia, C. Sanchez, AV. Kanaev, Thin Solid Films, 2003, 428, 257.

[27] Li Wang, Yong Pu, Wenqing Fang, Jiangnan Dai, Changda Zheng, Chunlan Mo, Chuanbin Xiong and Fengyi Jiang, Thin Solid Films, 2005,491, 323.

[28] ZQ. Chen, S. Yamamoto, M. Maekawa, A. Kawasuso, J Appl Phys 2003, 94, 4807.

[29] HP. Klug, LE. Alexaander, X-ray diffraction procedure for crystalline and amorphous materials. New York: Wiley; 1974, P662.

[30] L.P. Dai, H. Deng, G. Chen, C.F. Tang, M. Wei, Y. Li, Vacuum $2007,81,969$.

[31] JF. Chang, MH. Hon, Thin Solid Films 2001, 386, 79.

[32] J. Gonioakowski and C. Noguera, Surf. Sci. 1995, 340, 191.

[33] S. Russo and C. Noguera, Surf. Sci. 1992, 262, 259.

[34] A. Moses Ezhil Raj, L. C. Nehru, M. Jayachandran and C. Sanjeeviraja, Cryst. Res. Technol. 2007, 42, 867.

[35] RJ. Hong, JB. Huang, HB. He, ZX. Fan, JD. Shao, Appl Surf Sci, 2005, 242, 346.

[36] A.C. Wang, J.Y. Dai, J.Z. Cheng, M.P. Chudzik, T.J. Marks, R.P.H. Chang, C.R. Kannewurf, Appl Phys Lett 1998, 73, 327.

[37] QH. Li, Q. Wan, YX. Liang, TH. Wang. Appl Phys Lett 2004, 84, 4556. 